\title{
Differential Protein Expression Profiles in Glaucomatous Trabecular Meshwork: An Evaluation Study on a Small Primary Open Angle Glaucoma Population
}

\author{
Alessandra Micera • Luciano Quaranta - Graziana Esposito • \\ Irene Floriani · Augusto Pocobelli · Sergio Claudio Saccà · Ivano Riva • \\ Gianluca Manni · Francesco Oddone \\ To view enhanced content go to www.advancesintherapy.com \\ Received: October 30, 2015 / Published online: January 28, 2016 \\ (C) The Author(s) 2016. This article is published with open access at Springerlink.com
}

\section{ABSTRACT \\ Introduction: Primary open angle glaucoma (POAG) is a progressive optic neuropathy characterized by impaired aqueous outflow and extensive remodeling in the trabecular meshwork (TM). The aim of this study was to}

Electronic supplementary material The online version of this article (doi:10.1007/s12325-016-0285-x) contains supplementary material, which is available to authorized users.

A. Micera - G. Esposito · F. Oddone

IRCCS-G.B. Bietti Foundation, Rome, Italy

L. Quaranta $(\varangle) \cdot$ I. Riva

Department of Medical and Surgical Specialties, Radiological Sciences and Public Health, Section of Ophthalmology, University of Brescia, Brescia, Italy e-mail: luciano.quaranta@unibs.it

I. Floriani

Laboratory of Clinical Research, IRCCS, Istituto di Ricerche Farmacologiche Mario Negri, Milan, Italy

A. Pocobelli

San Giovanni Hospital Complex, Eye Bank, Rome, Italy

S. C. Saccà

Ophthalmology Unit, Department of Head and

Neck Pathologies, St. Martino Hospital, Genoa, Italy

G. Manni

Department of Clinical Science and Translational

Medicine, University Tor Vergata, Rome, Italy characterize and compare the expression patterns of selected proteins belonging to the tissue remodeling, inflammation and growth factor pathways in ex vivo glaucomatous and post-mortem TMs using protein-array analysis.

Methods: TM specimens were collected from 63 white subjects, including 40 patients with glaucoma and 23 controls. Forty POAG TMs were collected at the time of surgery and 23 post-mortem specimens were from non-glaucomatous donor sclerocorneal tissues. Protein profiles were evaluated using a chip-based array consisting of 60 literature-selected antibodies.

Results: A different expression of some factors was observed in POAG TMs with respect to post-mortem specimens, either in abundance (interleukin [IL]10, IL6, IL5, IL7, IL12, IL3, macrophage inflammatory protein $[\mathrm{MIP}] 1 \delta / \alpha$, vascular endothelial growth factor [VEGF], transforming growth factor beta 1 [TGF $\beta 1$, soluble tumor necrosis factor receptor I [sTNFRI]) or in scarcity (IL16, IL18, intercellular adhesion molecule 3 [ICAM3], matrix metalloproteinase-7 [MMP7], tissue inhibitor of metalloproteinase 1 [TIMP1]). MMP2, MMP7, TGF $\beta 1$, and VEGF expressions 
were confirmed by Western blot, zymography, and polymerase chain reaction. No difference in protein profile expression was detected between glaucomatous subtypes.

Conclusion: The analysis of this small TM population highlighted some proteins linked to POAG, some previously reported and others of new detection (IL7, MIPs, sTNF $\alpha$ RI). A larger POAG population is required to select promising disease-associated biomarker candidates.

Funding: This study was partially supported by the Fondazione Roma, the Italian Ministry of Health and the "National 5xMille 2010 tax donation to IRCCS-G.B. Bietti Foundation".

Keywords: Extracellular matrix; Intraocular pressure; Primary open angle glaucoma; Trabecular meshwork

\section{INTRODUCTION}

Primary open angle glaucoma (POAG), the most common form of glaucoma, is a multifactorial disease with unclear pathogenesis, characterized by retinal ganglion cell death and irreversible damage of the optic nerve [1, 2]. Elevated intraocular pressure (IOP) represents the main risk factor involved in the onset and progression of POAG, due to an imbalance between aqueous humor production and outflow [3, 4]. POAG trabecular meshwork (TM) displays chronic inflammation and long-standing tissue remodeling $[5,6]$. These molecular events are mainly of endogenous origin and related to the long-term accumulation of oxidative damages arising from mitochondrial failure and endothelial dysfunction [7]. Proteins deriving from the damage occurring in endothelial TM cells underwent dramatic variation, reflecting oxidative damage, mitochondrial damage, neural degeneration, and apoptosis [8, 9]. Structural changes encompass extensive extracellular matrix (ECM) deposition, typified by increased collagen, fibronectin and elastin deposition (thickness of trabecular sheets), impaired growth factors release, unbalance in ECM enzymes and unusual myofibroblast development [10-15]. Apoptosis of endothelial cells and targets of oxidative stress (glyceraldehyde-3-phosphate dehydrogenase [GAPDH], a glycolytic enzyme; heat shock $70 \mathrm{kDa}$ protein 1 [HSP72], a stress protein; and glutamine synthetase, an excitotoxicity-related protein) were detected in POAG TMs, supporting the presence of a continuous inflammation, remodeling and immune system activation $[16,17]$. While many components of TM ECM have been identified, only few studies address the entire TM proteome. Cumulating data point to impaired synthesis/release of transforming growth factor beta (TGF $\beta$ s), nerve growth factor (NGF), vascular endothelial growth factor (VEGF), connective tissue growth factor (CTGF), tumor necrosis factor alpha (TNF $\alpha$ ), interleukin (IL) $1 \alpha$, IL2, IL8, fibroblast growth factor (FGF), and their receptors, detected by single conventional approaches [18-22]. Some pro-inflammatory/fibrogenic factors have been detected in the aqueous humor, suggestive of future applications [23-25].

To date, the mechanism and the molecular basis responsible for structural, biochemical, and functional changes occurring in glaucomatous TM are poorly understood [26, 27]. Several studies have been performed to identify systemic and local biochemical risk factors and some novel protein/antibody profiles have been prospected as potential targets to counteract the degenerative effects in POAG, in addition to the IOP [3, 4, 28]. Recently, the protein microarray approach has 
highlighted, most resourceful than conventional approach, some candidates (biomarkers) for POAG, pertinent to routine diagnostic applications/monitoring of treatment efficacy or to target therapy $[18,29$, 30].

The aim of the present study was to explore the expression of some factors in TMs from patients with POAG.

\section{METHODS}

\section{Ethics Statement}

All procedures followed were in accordance with the ethical standards of the responsible committee on human experimentation (institutional and national), with the Helsinki Declaration of 1964, as revised in 2013, and was reviewed/approved by the institutional Ethic Committee (IRCCS IFO-Fondazione Bietti). A written informed consent was signed by patients joining the study and undergoing surgical therapy.

\section{POAG Population}

A total of 40 POAG and 23 age/sex-matched post-mortem TM specimens were used for the study (Table 1). Both slit lamp and clinical data were collected the day before surgery from each patient including age, gender, ocular history, diagnosis and duration of disease, previous medications, IOP, visual acuity and other ocular surgical interventions. The inclusion criteria comprised patients who needed to undergo trabeculectomy for uncontrolled IOP under maximal tolerated topical medical therapy, while the exclusion criteria comprised patients with systemic (either inflammatory, autoimmune and/or immunosuppressive) or pre-existing ocular (retinal vein/artery occlusion, diabetic retinopathy and age-related macular degeneration) diseases, or previous trabeculectomy or other ocular surgery or use of topical or systemic corticosteroids. All POAG $\mathrm{TM}$ samples were further grouped according to the IOP-lowering topical therapy ongoing before glaucoma surgery [Group $1 \quad(n=14)$ :

Table 1 Patient's main characteristics

\begin{tabular}{lll}
\hline Characteristics & POAG $^{\mathbf{a}}$ & Control \\
\hline Population & 40 & 23 \\
Male/female & $17 / 23$ & $15 / 8$ \\
Mean age (years) & $69.25 \pm 9.49$ & $74.25 \pm 7.94$ \\
Mean ( \pm range) IOP, mm Hg & $19.83 \pm 4.55$ & - \\
Surgery: trabeculectomy/phacoemulsification & $11 / 29$ & None $^{\text {b }}$ \\
Previous therapy $^{c}$ & IOP-lowering eye drop & None \\
\hline
\end{tabular}

All data are shown as mean \pm standard deviation

$I O P$ intraocular pressure, $P O A G$ primary open angle glaucoma

a Both inclusion and exclusion criteria are detailed in the "Methods" section

b The non-glaucomatous control TMs were dissected out by mimicking trabeculectomy and phaco-trabeculectomy surgery on sclerocorneal specimens (EyeBank)

c Medications are listed in the "Methods" section 
prostaglandin analogs (PGE) + carbonic anhydrase inhibitors (CAI); Group $2(n=26)$ : PGE + CAI + beta-blockers (BB)].

All analytical grade reagents and sterile plastic-ware were from SERVA (Weidelberg, Germany), ICN (Costa Mesa, CA, USA), Euroclone (Milan, Italy), Sigma-Aldrich (St. Louis, MO, USA) and NUNC (Roskilde, Denmark), unless otherwise specified. Ultrapure Milli-Q Grade Water was daily provided by the DirectQ 5 apparatus (Millipore, Vimodrone, Italy).

\section{POAG and Post-mortem TM Specimens}

Pathological TMs were collected from patients who underwent surgical procedures $(n=10$ from trabeculectomy and $n=25$ from phacotrabeculectomy) and quickly stabilized in a storage buffer (50 mM Tris-buffer, $150 \mathrm{mM}$ $\mathrm{NaCl}, 1 \mathrm{mM}$ EDTA, 10\% glycerol) supplemented with protease inhibitors (\#78410; Pierce Biotechnology, Rockford, IL) and stored at $-70{ }^{\circ} \mathrm{C}$. Delivery to the Laboratory Unit was performed according to a standardized procedure, avoiding sample thawing and protein degradation.

Control samples, made available by the Eye Bank of Rome (Italy), were obtained from organ donors undergoing removal of eyes for corneal transplant, within $6 \mathrm{~h}$ of death and provided in Eusol-C medium (herein shorten as post-mortem samples). The absence of any eye diseases in these donors was ascertained in agreement with Italian national law (No. 301 of 12 August 1993). Briefly, four representative TMs were collected for each specimen under a dissector microscope (SMZ645; Nikon, Tokyo, Japan) equipped with cold-light optic fibers (PL2000 photonic; Axon, Vienna, Austria), reproducing accurately the procedure of trabeculectomy and quickly stored in inhibitor-supplemented storage buffer at
$-70{ }^{\circ} \mathrm{C}$ until using in parallel with POAG samples. All post-mortem TMs were quickly stabilized in appropriate buffer, similar to POAG specimens.

Additional 5 glaucomatous $(n=2$ from trabeculectomy and $n=3$ from phacotrabeculectomy) and 5 post-mortem specimen were sampled in Thin Prep (Cytyc Corp., Milan, Italy) and subjected to molecular analysis.

\section{Total Protein Extraction and Sodium Dodecyl Sulphate-Polyacrylamide Gel Electrophoresis, (SDS-PAGE) Analysis}

Enzymatic pre-digestion was used to extract protein from each specimen $(n=35$ POAG and $n=18$ post-mortem samples). Briefly, TM specimens were treated with dispaseII $(2 \mu \mathrm{g} / \mathrm{mL}$ in HBSS without $\mathrm{Ca}^{2+}$ and $\mathrm{Mg}^{2+}$ ) for $15 \mathrm{~min}$ at $37^{\circ} \mathrm{C}$, diluted $1: 1(\mathrm{v} / \mathrm{v})$ with $2 \times$ Lysis buffer (25 mM Tris-buffer, $150 \mathrm{mM} \mathrm{NaCl}, \quad 0.1 \%$ Tween20, $1 \mathrm{mM}$ EDTA, 10\% glycerol, 0.1\% SDS, $10 \mathrm{mM} \mathrm{NaF}$ and $1 \mathrm{mM}$ PMSF; $\mathrm{pH}$ 7.5), homogenized with a Polytron $\left(25 \mathrm{~s} / 0^{\circ} \mathrm{C}\right.$ at 21500 rev./min; Ultra Turrax T25 basic; IkaWerke, Staufen, Germany) and briefly sonicated to shear DNA/RNA (VibraCell, Sonics, Newtown, CT, USA). Tissue lysates were clarified by centrifugation and protein amount/quality was analyzed using the Nanodrop Spectrophotometer (A1000; Celbio, Milan, Italy). Protein amounts were detected with the A280-Nanodrop option by means of common internal standards, after "blank" options against water and extraction buffer. Data $(\mu \mathrm{g} / \mu \mathrm{L})$ were used to normalize protein extracts before loading in the specific assay.

SDS-PAGE was performed under reducing (electrophoretic profile) conditions on a 4-12\% precasted-SDS mini gel (MiniProtean III apparatus; Biorad Laboratories Inc, Hercules, 
CA, USA). Separated bands were transblotted to Hybond membranes (Amersham Biosciences; GE Healthcare, Buckinghamshire, England) under semidry conditions (Transblot apparatus; Biorad). Membranes were stained with the Ponceau $\mathrm{S}$ solution (SERVA). Whenever required, protein extracts were concentrated according to the 500 VivaSpin manufacturers' recommendations (Sartorius AG, Goettingen, Germany). Some samples were subject to IgG removal according to a standard procedure (GE Healthcare) [31].

\section{Chip-Based Arrays for Proteome Analysis}

The proteome array was performed on customized chip-based arrays provided on glass-slides, according to the manufacturers' procedures with minor modifications (RayBio technology; Norcross, CA). Each glass-slide (array) comprised 14 identical subarrays containing 60 biomarkers assembled on demand. The scheme of each chip is reported in Fig. 2a. Inter-assay normalization was conducted by including multiple positive markers and negative controls for each sub-array. The minimum sensitivity range for detection of each protein varied, ranging from 3.8 to $56 \mathrm{pg} / \mathrm{mL}$.

For hybridization, an equal amount of protein extracts $(350 \mathrm{ng} / \mathrm{mL}$ in Lysis Buffer) was applied to each sub-array (70 $\mu \mathrm{L} /$ subarray). Both POAG ( $n=25$ POAG) and control $(n=13)$ extracts were processed in parallel. After an overnight incubation at $4{ }^{\circ} \mathrm{C}$, the array slides were washed and exposed to a biotinylated antibody mixture followed by a cy3-streptAvidin labeling solution. All steps were performed under orbital shaking (CertomaxII, Sartorius AG) and all the hybridization/washing solutions were provided by the kit. As a final point, the glass-slides were washed once with MilliQ water, spin-dried and acquired with a GenePix 4400 Microarray scanner (Molecular Devices LLC, Sunnyvale, Silicon Valley, CA). To obtain appropriate Cy5 (background signal) and Cy3 (specific signal) images, the slides were scanned over previously validated acquisition parameters and the images/arrays (blocks) were uniformly adjusted for size, brightness and contrast at the moment of acquisition. Using the SPOT tool, the specific area (corresponding to each cytokine on the array) was manually spotted and automatically adjusted, according to prefixed acquisition parameters applied to all glass-slides of the study. The fluorescent intensity data (FI) of each spot was calculated by the GenePix Pro 6.0 pro software (Molecular Devices), that provide background-subtracted FI data (F532-B532, N factor) as of a value for spot volume representing the product of the area and the highest pixel value contained in that area.

\section{Confirmation Experiments by Western} Blot, Zymography, and Real-Time PCR

\section{Western Blotting}

The membranes from electrophoretic analysis were equilibrated in $0.5 \%$ Triton, blocked in 3\% BSA, incubated with the primary antibodies (0.2-0.8 $\mu \mathrm{g} / \mathrm{mL}, 18 \mathrm{~h}$; MMP2 (sc-10736) and MMP7 (sc-130819) were from Santa Cruz; TGFß1 (mab240) and VEGF (AF-293-NA) were purchased from R\&D Systems, Minneapolis, Il) and labeled with secondary specie-specific POD-conjugated antibodies (1/7000, $90 \mathrm{~min}$; Jackson Laboratories, West Grove, PA). The specific signals were visualized by SuperSignal West Pico Trial (Pierce).

\section{Zymography}

To study MMP2 and MMP9 functional activity, tissue extract were three fold-concentrated 
(VivaSpin) and pre-mixed with 5X Loading buffer under non-reducing conditions and incubated at $37^{\circ} \mathrm{C}$ over $30 \mathrm{~min}$. Normalized protein extracts ( $20 \mu \mathrm{L} /$ lane) were pre-incubated at $37^{\circ} \mathrm{C}$ over $30 \mathrm{~min}$. Samples were then fractioned on $7-10 \%$ SDS-PAGE gels containing $0.1 \%$ gelatin $(1 \mathrm{mg} / \mathrm{mL}$ gelatin), under non-reducing condition (frontline/ $130 \mathrm{~V})$. Gels were washed in rinse-buffer (15 min; $50 \mathrm{mM}$ Tris- $\mathrm{HCl}, 10 \mathrm{mM} \mathrm{CaCl}_{2}$ and 2.5\% Triton X-100; $\mathrm{pH} 7.2$ ) to promote recovery of protease activity and briefly rinsed with distilled water before incubating in substrate buffer $\left(24 \mathrm{~h} / 37^{\circ} \mathrm{C}\right.$; $50 \mathrm{mM}$ Tris-HCl, $150 \mathrm{mM}$ $\mathrm{NaCl}, 10 \mathrm{mM} \mathrm{CaCl}$, $1 \%$ Triton-X100; $\mathrm{pH}$ 7.2). Gels were stained with $0.5 \%$ Coomassie blue R-250 in 30\% isopropanol and 10\% acetic acid for $30 \mathrm{~min}$ to $2 \mathrm{~h}$ and then de-stained in 10\% isopropanol and 10\% acetic acid until clear bands were visible. Internal controls and size marker were run in parallel. Molecular weights of the bands were estimated through the use of prestained molecular-weight markers MMP2 and MMP9 activity was identified as clear bands (white bands over a blue background) corresponding to degraded substrate.

Membranes and zymograms were captured in a 1D Kodak Image station (Kodak 550, Eastman Kodak Company, Sci. Imaging Systems, Rochester, NY, USA) and exported as 16-tiff converted images (1D Kodak Image Analysis Software). Single integrated optical density values (Intdensity) were registered for each group by means of 1D ImageJ software (ImageJ ver. 1.43; NIH-http://rsb.info.nih.gov/ ij/) and assembled with minor modifications by Adobe photoshop 7.0 (Abacus concepts).

\section{Real-Time PCR}

RNA extraction was performed by Proteinase K predigestion and EuroGold TRIfast extraction, according to the manufactures' procedure
(EuroClone, Pero, Milan, Italy). Equivalent total RNAs (170 ng; 260/280 rate $>1.8$; Nanodrop) were used for cDNA synthesis that were carried out using $50 \mathrm{pM}$ random primers and 200 U Reverse Transcriptase (IM-PROM kit, Promega, Milan, Italy) in a programmable PCR thermocycler (Primus 25 advanced-PCR; Peqlab LLC., Wilmington, USA). SYBR Green PCR amplifications (Applied Biosystems, Foster City, CA, USA) were run in a PCR Opticon2 (MJ Research, Watertown, MA), according to a standard protocol. The specific primers used were as follows: MMP2, MMP7, TGF $\beta 1$, VEGF, $18 \mathrm{~S}, \mathrm{H} 3$, and $\beta 2 \mathrm{MG})$. Negative/positive controls and single-mode melting curves were used to validate the amplifications.

\section{Statistical Analysis}

POAG and post-mortem TMs were analyzed in duplicate (spots/bands) and mean values $( \pm S D)$ were calculated from these replicates. Individual biomarker expression was provided by GenePix software. The row spot intensity data were entered into a Microsoft Excel database (Microsoft, Redmond, WA) and duplicate spots outside the $10 \%$ coefficient of variability were refused from the statistical analysis. FDR value of 0.01 , as observed. Protein response ratios were defined as the variation in a given marker and a cut-off of two fold (changes) was used for differential expression, in accordance with previously published methods [32, 33]. The non-parametric Mann-Whitney $U$ test was selected according to the small size population. Statistical significance for intra-pair POAG analysis was set at $p<0.00083$ to control for multiple testing $(p=0.05 / 60$ targets) and at $p \leq 0.05$ for WB, Zymography and real-time PCR. The SPSS 15.0 statistic package (SPSS Inc, Chicago, IL, USA) was used for all comparisons. A specific REST/ 
Mann-Whitney $U$ test coupled analysis was carried out for PCR experiments.

\section{RESULTS}

A total of 40 POAG and 23 post-mortem TM specimens were analyzed (Table 1$)$. As detected in pilot studies, $17 \%$ (8/40 extracted specimens) of the total TM extracted samples was undetectable. The entire experimental procedure of this lower-case project, procedure, including TM stabilization to reduce protein degradation during transit, is shown in Fig. 1a. The total protein amount was detectable in all specimens included in the study, and representative spectrophotometer plots are shown in Fig. 1b. The electrophoretic analysis of POAG TM revealed the presence of

\title{
a Trabecular Meshwork
}

\author{
collection and stabilization \\ in protease inhibitors
}

enzymatic and mechanical Tissue digestion

protein extraction

analysis $(b, c)$

protein profile analysis (chip array hybridization)

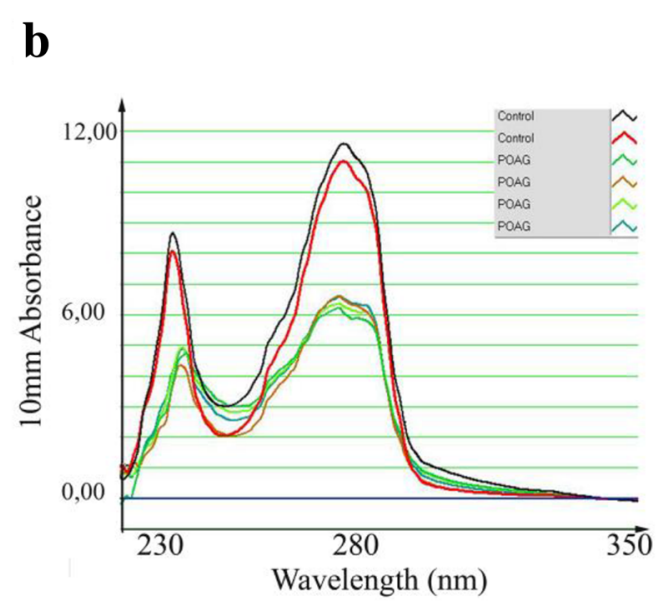

Fig. 1 Experimental procedure and total protein analysis. a POAG and post-mortem TM specimens were simultaneously processed, according to the procedure reported in the "Methods" section. b Representative A280 plot showing the digital spectrophotometer outputs. Small peaks in the tract represent a small proportion of contaminants (solvents and salts; left side). c Comparative c

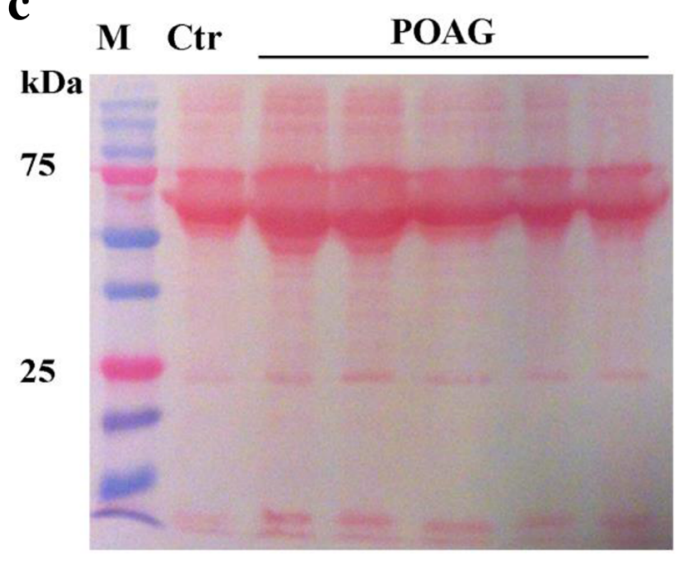

TM protein profiles by 1D SDS-PAGE analysis (representative membrane), from randomly selected POAG and post-mortem specimens generated after the enzymatic digestion procedure. Note the presence of bands resembling IgG proteins. $P O A G$ primary open angle glaucoma, $S D S-P A G E$ sodium dodecyl sulphate-polyacrylamide gel electrophoresis, $T M$ trabecular meshwork 
a

\begin{tabular}{|c|c|c|c|c|c|c|c|c|c|c|c|c|c|c|}
\hline & $A$ & $B$ & $c$ & $D$ & $E$ & $E$ & $G$ & $\boldsymbol{H}$ & $I$ & $J$ & $\boldsymbol{K}$ & $I$ & $M$ & $N$ \\
\hline 1 & $\cos 1$ & $\operatorname{RCS} 2$ & $\operatorname{ECS} 3$ & NEG & NEG & $\mathrm{TNF} \alpha$ & IFNY & IL1 $\beta$ & IL2 & IL3 & IL4 & IL5 & IL6 & IL7 \\
\hline 2 & $\operatorname{ROS} 1$ & $\operatorname{RCs} 2$ & $\operatorname{ECS} 3$ & NEG & NEG & TNE $\alpha$ & IFNY & IL1 $\beta$ & IL2 & IL3 & IL4 & IL5 & IL6 & IL7 \\
\hline 3 & IL8 & IL9 & IL10 & $\begin{array}{c}\text { IL12 } \\
\text { P40 }\end{array}$ & $\begin{array}{c}\text { IL12 } \\
\text { p70 }\end{array}$ & IL17 & IL18 & MMP1 & MMP2 & MPP 7 & MMP9 & MMP13 & TIMP1 & TIMP2 \\
\hline 4 & IL8 & IL9 & IL10 & $\begin{array}{c}\text { IL12 } \\
\text { p40 }\end{array}$ & $\begin{array}{c}\text { IL12 } \\
\text { p70 }\end{array}$ & IL17 & IL18 & MMP1 & MP2 & MPP & MP9 & MMP13 & TIMP1 & TIMP2 \\
\hline 5 & TIMP4 & $\begin{array}{c}\text { Eotaxin } \\
1\end{array}$ & $\begin{array}{c}\text { Eotaxin } \\
2\end{array}$ & RANIFS & TacE & MIPl $\alpha$ & MIP1 $\beta$ & MIP1б & $\operatorname{MIP} 3 \alpha$ & MIP3 $\beta$ & TLR2 & IL33 & IL34 & Insulin \\
\hline 6 & TIMP4 & $\begin{array}{c}\text { Eotaxin } \\
1\end{array}$ & $\begin{array}{c}\text { Eotaxin } \\
2\end{array}$ & RANIFAS & TACE & MII $1 \alpha$ & MIP1 $\beta$ & MIP1ठ & $\operatorname{MIP} 3 \alpha$ & MIP3 $\beta$ & TLR2 & IL33 & IL34 & Insulin \\
\hline 7 & VCAMI & NCAMI & ICAMI & ICAM2 & ICAMB & IL15 & IL16 & IL21 & STNERI & $\begin{array}{l}\text { STNF } \\
\text { RII }\end{array}$ & IP10 & $\beta \mathbf{N G F}$ & VEGE & TGEß1 \\
\hline 8 & VCAMI & NCAMI & ICAMI & ICAM2 & ICAMB & IL15 & IL16 & IL21 & STNERI & $\begin{array}{c}\text { sTNF } \\
\text { RII }\end{array}$ & IP10 & $\beta \mathbf{N G F}$ & VEGF & TGEß1 \\
\hline 9 & NT3 & NT4 & BDNE & bEGF & EGF & SCF & S100B & Albumin & NEG & NEG & NEG & NEG & NEG & Exs -2 \\
\hline 10 & NT3 & NT4 & BDNE & bFGE & EGF & SCE & S100B & Albumin & NEG & NEG & NEG & NEG & NEG & ECS-2 \\
\hline
\end{tabular}

b

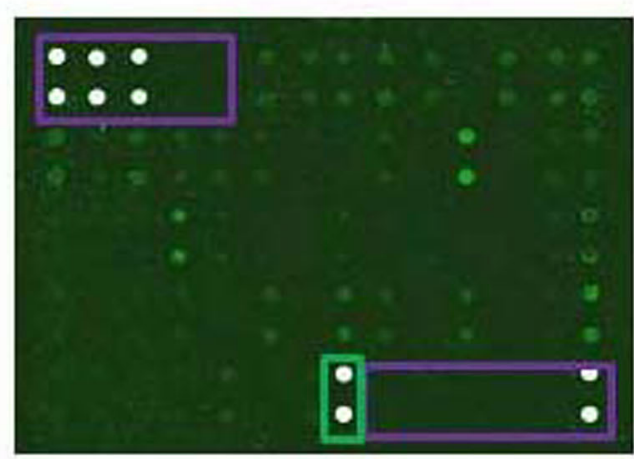

POAG

Fig. 2 Representative chip-based arrays. Chip are grids that contain small amounts of purified proteins in high density, hybridized to sample and detected by fluorescent technique. a The map showing the selected factors in a $14 \times 10$ grid. Each subarray contains 60 antibodies and specific positive/ negative referring spots. b, c Representative GenePix acquired arrays from POAG (b) and post-mortem (c) TM specimens, both loaded as normalized extracts. White points are positive technique controls (framed), dark points are negative technique controls and green points are c

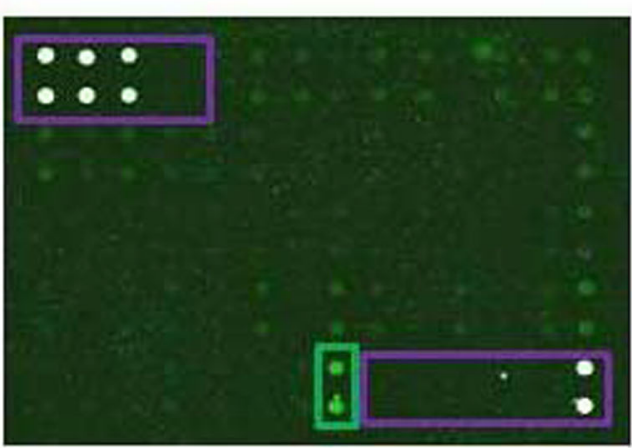

\section{ctr}

POAG/post-mortem TMs (cy3-labeled spots). Abbreviations of the main factors were according to International Classification. EGF epidermal growth factor, $I L$ interleukin, $M I P$ macrophage inflammatory protein, $M M P$ matrix metalloproteinase, $P O A G$ primary open angle glaucoma, $S C F$ stem cell factor, $S D S$ sodium dodecyl sulphate, TIMP tissue inhibitor of metalloproteinase, TLR toll-like receptor, $T M$ trabecular meshwork, $T N F$ tumor necrosis factor 
abundant bands at the 100, 90, 70 and $40 \mathrm{kDa}$. Both heavy and light IgG chains were observed in several protein extracts (SDS-PAGE; Fig. 1c) and samples showing over-expressed heavy/light Ig chains were pretreated prior to hybridization (see M\&M).

To facilitate the reading/analysis of chip-array grids in Fig. 2a, appropriate clusters were defined. Two representative cy3-labeled fluorescence subarrays are reported in Fig. 2b, c, showing a significant increase of IF in POAG subarrays (B) with respect to post-mortem ones (C). The non-parametric Mann-Whitney two-sided $U$ test was employed to select factors of significant value. The full data are available in Table 2, including single fold cut-offs and $p$ values (>two fold changes and $p \leq 0.00083$ ) provided in clusters as follows: cytokines; neurotrophins, fibrogenic and angiogenic factors; chemokines/adhesion molecules; ECM metabolism, metalloproteinases and tissue-inhibitory factors and other molecules, including soluble receptors and some referring proteins. A total of 32 out of 60 potential candidates were significantly associated with POAG. Most of them were represented by cytokines (IL10, IL6, IL5, IL7, IL12p40/70), chemokines (VCAM1, MIP1 $\alpha / \delta$ ) and growth factors (TGF $\beta 1$, VEGF), showing high expression levels ( $>$ five fold) in POAG TMs, as compared to non-glaucomatous ones ( $p<0.00083 ; \quad$ Mann-Whitney $U$ test $)$. Moreover, IL16, IL18 and ICAM3 showed negative values, as compared to controls $(p<0.00083 ; \quad$ Mann-Whitney $U$ test). Regarding the ECM enzymes, a significant expression was detected for MMP2 while a low expression was quantified for MMP7 and TIMP1 (>two fold changes; $p<0.00083$; Mann-Whitney $U$ test). No difference in protein profile expression was observed between the two IOP-lowering subgroups
(Group 1 and Group 2; $p>0.00083$, Mann-Whitney $U$ test), nor between the two different surgical approaches (trabeculectomy and phacotrabeculectomy; $p>0.00083$, Mann-Whitney $U$ test).

To better understand ECM metabolism and fibrosis/angiogenesis in glaucomatous TMs, MMPs 2/9/7 and TIMP1 as well as TGF $\beta 1$, VEGF were selected for Western Blot, Zymography and real-time PCR analysis. The Western Blot analysis showed as follows: increased expression for MMP2 $(+1.39 \pm 0.02$ folds; $p<0.05)$, TGF $\beta 1 \quad(+2.00 \pm 0.53$ folds; $p<0.05)$ and VEGF $(+2.13 \pm 0.41$ folds; $p<0.05)$; unchanged expression for MMP7 $(+0.50 \pm 0.39$ folds; $p>0.05) ;$ and decreased expression for MMP9 $(-3.71 \pm 2.54$ folds; $p<0.05)$, TIMP1 $(-1.43 \pm 0.33$ folds; $p<0.05)$. Zymography (a functional test) identified bands of gelatinolytic activity, respectively, at 66 and $72 \mathrm{kDa}$, corresponding to the active and pro MMP2, respectively, at 80 and $92 \mathrm{kDa}$, corresponding to the active and pro MMP9 (Fig. 3). A high MMP9 gelatinolytic activity was also detected in non-glaucomatous control extracts (post-mortem specimens). Finally, the relative real-time PCR supported $(p<0.05)$ the increased expression of MMP2 $(+2.53 \pm$ $\left.0.02_{2 \log \text {-ratio }}\right)$, TGF $\beta 1\left(+5.27 \pm 0.03_{2 \log \text {-ratio }}\right)$ and VEGF $\left(+2.84 \pm 0.16_{2 \text { log-ratio }}\right)$, and highlighted the deregulation of MMP7 $\left(-3.77 \pm 0.06_{2 \log \text {-ratio }}\right)$.

\section{DISCUSSION}

POAG represents one of the major leading causes of blindness worldwide, with poor early diagnosis and prognosis [1, 2, 28, 34]. Currently, no therapy is curative and an early diagnosis and/or a prompt intervention in "risk patients" would contribute significantly to reduce the progression of disease [1, 2, 24]. 
Table 2 Protein profile expression

\begin{tabular}{|c|c|c|}
\hline Protein & Folds & $p$ value \\
\hline \multicolumn{3}{|l|}{ Cytokines } \\
\hline IL10 & 23.81 & $2.84 \mathrm{E}-07$ \\
\hline IL6 & 14.57 & $2.84 \mathrm{E}-07$ \\
\hline IL5 & 13.27 & $2.84 \mathrm{E}-07$ \\
\hline IL7 & 12.51 & $2.84 \mathrm{E}-07$ \\
\hline IL12p70 & 8.74 & $2.84 \mathrm{E}-07$ \\
\hline IL12p40 & 7.72 & $2.84 \mathrm{E}-07$ \\
\hline IL3 & 4.43 & $2.84 \mathrm{E}-07$ \\
\hline IL21 & 3.71 & $2.84 \mathrm{E}-07$ \\
\hline IL4 & 3.70 & $2.84 \mathrm{E}-07$ \\
\hline IL33 & 3.25 & $2.84 \mathrm{E}-07$ \\
\hline $\mathrm{TNF} \alpha$ & 2.48 & $5.52 \mathrm{E}-07$ \\
\hline$\gamma \mathrm{IFN}$ & 2.28 & $5.52 \mathrm{E}-07$ \\
\hline IL15 & 2.22 & $2.84 \mathrm{E}-07$ \\
\hline IL2 & 2.14 & $5.52 \mathrm{E}-07$ \\
\hline $\operatorname{IL} 1 \beta$ & 1.71 & $1.10 \mathrm{E}-04$ \\
\hline IL17 & 1.64 & $1.06 \mathrm{E}-05$ \\
\hline IL8 & 1.45 & $3.18 \mathrm{E}-06$ \\
\hline IL34 & 1.34 & $1.70 \mathrm{E}-03$ \\
\hline IL9 & 1.01 & NSS \\
\hline IL18 & -11.79 & $2.16 \mathrm{E}-05$ \\
\hline IL16 & -43.65 & $5.03 \mathrm{E}-06$ \\
\hline \multicolumn{3}{|c|}{ Neurotrophins, fibrogenic, and angiogenic factors } \\
\hline VEGF & 6.10 & $9.01 \mathrm{E}-07$ \\
\hline TGF $\beta 1$ & 6.07 & $2.84 \mathrm{E}-07$ \\
\hline NT3 & 4.73 & $3.08 \mathrm{E}-07$ \\
\hline$\beta \mathrm{FGF}$ & 3.92 & $1.84 \mathrm{E}-04$ \\
\hline$\beta N G F$ & 3.84 & $2.84 \mathrm{E}-07$ \\
\hline Insulin & 3.33 & $1.46 \mathrm{E}-06$ \\
\hline $\mathrm{BDNF}$ & 3.13 & $2.84 \mathrm{E}-07$ \\
\hline NT4 & 2.96 & $2.84 \mathrm{E}-07$ \\
\hline SCF & 1.32 & NSS \\
\hline
\end{tabular}

Table 2 continued

\begin{tabular}{lrl}
\hline Protein & \multicolumn{1}{l}{ Folds } & $\boldsymbol{p}$ value \\
\hline EGF & -1.51 & NSS \\
ECM metabolism & & \\
MMP2 & 3.18 & $2.84 \mathrm{E}-07$ \\
MMP1 & 2.00 & $2.84 \mathrm{E}-07$ \\
TIMP2 & 1.79 & $5.03 \mathrm{E}-06$ \\
MMP13 & 1.27 & NSS \\
TIMP4 & -1.28 & NSS \\
MMP9 & -1.35 & NSS \\
MMP7 & -2.03 & $2.81 \mathrm{E}-04$ \\
TIMP1 & -2.18 & $8.76 \mathrm{E}-04$
\end{tabular}

Chemokines/adhesion molecules

\begin{tabular}{lrl} 
VCAM1 & 7.29 & $2.84 \mathrm{E}-07$ \\
MIP1 $\delta$ & 7.04 & $3.35 \mathrm{E}-07$ \\
MIP1 $\alpha$ & 5.51 & $2.84 \mathrm{E}-07$ \\
Eotaxin1 & 2.61 & $3.18 \mathrm{E}-06$ \\
ICAM1 & 2.16 & $1.51 \mathrm{E}-05$ \\
TACE & 2.01 & $2.84 \mathrm{E}-07$ \\
RANTES & 1.94 & $1.23 \mathrm{E}-03$ \\
ICAM2 & 1.91 & $1.88 \mathrm{E}-05$ \\
Eotaxin2 & 1.69 & NSS \\
MIP3 $\beta$ & 1.50 & $5.83 \mathrm{E}-03$ \\
NCAM1 & 1.46 & NSS \\
MIP3 $\alpha$ & -1.14 & NSS \\
MIP1 $\beta$ & -1.73 & $1.84 \mathrm{E}-04$ \\
ICAM3 & -8.90 & $6.50 \mathrm{E}-07$ \\
Other molecules & & \\
sTNFR I & 4.41 & $4.68 \mathrm{E}-07$ \\
Albumin & 1.84 & NSS \\
S100B & 1.80 & $5.83 \mathrm{E}-03$ \\
IP10 & 1.77 & $1.41 \mathrm{E}-05$ \\
sTNFR II & 1.03 & NSS \\
\hline
\end{tabular}


Table 2 continued

\begin{tabular}{lll}
\hline Protein & Folds & $\boldsymbol{p}$ value \\
\hline TLR2 & -1.21 & $3.26 \mathrm{E}-01$ \\
\hline
\end{tabular}

Mann-Whitney $U$ test analysis with both POAG/ctr fold-changes $(\geq 2)$ and $p$ values $(\leq 0.00083$, see "Methods" section) for each biomarker in POAG TMs. NSS for results having $p$ values $>8.3 \mathrm{E}-04$. The factors are listed for higher to lower expression. The ECM metabolism cluster included both metalloproteinases and their specific inhibitors, and the cluster other molecules comprised soluble receptors and some referring proteins

$B D N F$ brain-derived neurotrophic factor, $E C M$ extracellular matrix, $E G F$ epidermal growth factor, $F G F$ fibroblast growth factor, ICAM intercellular adhesion molecule, IFN interferon, IL interleukin, IP interferon gamma-induced protein, $M I P$ macrophage inflammatory protein, $M M P$ matrix metalloproteinase, NCAM neural cell adhesion molecule, $N G F$ nerve growth factor, $N S S$ not statistically significant, $N T$ neurotrophin, $P O A G$ primary open angle glaucoma, RANTES regulated on activation, normal T cell expressed and secreted, $S C F$ stem cell factor, sTNFR soluble tumor necrosis factor receptor, $T A C E$ TNF- $\alpha$ converting enzyme, TLR toll-like receptor, TIMP tissue inhibitor of metalloproteinase, $T N F$ tumor necrosis factor, $T M$ trabecular meshwork, $V C A M$ vascular cell adhesion molecule, $V E G F$ vascular endothelial growth factor

Sustained high-IOP levels or recurrent TM inflammation/remodeling or even long-standing homeostatic adjustments could trigger atypical cell-cell, cell-protein and/or protein-protein interactions, leading to $\mathrm{TM}$ structural changes in POAG [17, 35]. Several genes/proteins (soluble and stress-related mediators, growth factors, cytoskeletal and ECM-associated proteins) have been identified in POAG (mainly in TM-derived cells, aqueous humors, tears and blood) and proposed as potential candidates for the prognosis of disease and monitoring of therapy [24, 36].

Since any effort in the characterization of POAG-associated protein profile will be of great importance in understanding the mechanisms underlying POAG progression, a nonbiased chip-based microarray approach was carried out to discriminate 60 antibodies for potential proteins/factors relevant to pathological TM. The selected potential candidates are all known to be involved in chronic inflammation and tissue remodeling [16, 24, 28, 31, 36-39].

To the best our knowledge in literature, this is the first study conducted in vivo on human normal and glaucomatous TMs. From this comparative analysis, 32 out of 60 explored candidates were significantly affected in POAG specimens, as compared to control specimens dissected out from non-glaucomatous

\section{POAG}

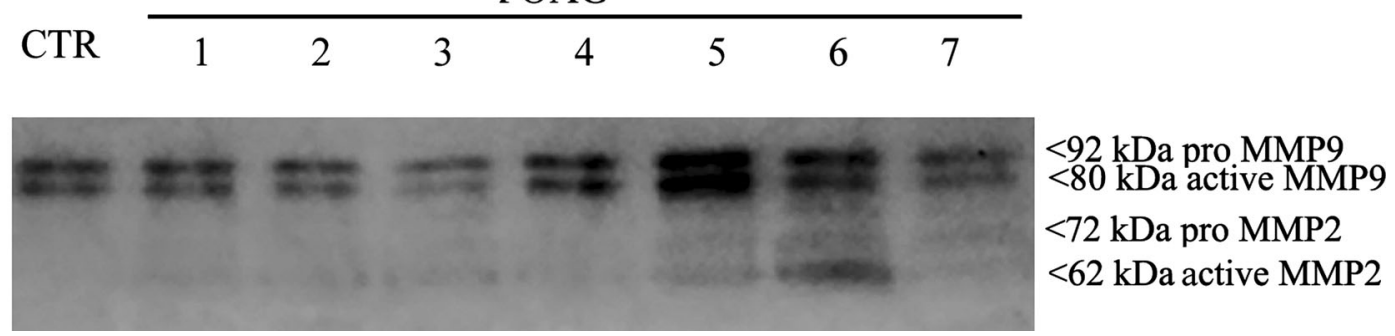

Fig. 3 Confirmation of gelatinolytic activity of MMPs. Non-glaucomatous post-mortem and POAG TM $(n=7$; lanes 1-7) extracts were electrophoresed on a gelatincontaining SDS gels (see the "Methods" section). Note the presence of gelatinolytic activity at $80 / 92 \mathrm{kDa}$ (active/pro MMP9) and 62/72 (active/pro MMP2). Representative zymogram from three similar experiments. Both 80 and
$92 \mathrm{kDa}$ MMP9 bands are clearly visible in control TMs. Distinct 62 and $72 \mathrm{kDa}$ bands specific for MMP2 were not detected in post-mortem extracts, while specific bands occur in POAG extracts. MMP matrix metalloproteinase, $P O A G$ primary open angle glaucoma, $T M$ trabecular meshwork 
sclerocorneal explants mimicking the surgical procedure (see Table 2). Particularly, some cytokines (IL10, IL6, IL7, IL12p40/70, VCAM1, MIP1 $\delta / \alpha$, sTNFRI) as well as Th1/Th2- (IL2, IL3, IL4, IL5) and tissue remodeling- (MMP2, VEGF, TGF $\beta_{1}$ ) related proteins were significantly increased. This increase would suggest the presence of both chronic inflammatory and tissue remodeling process in these glaucomatous TM specimens. The observation of increased TNF $\alpha, \gamma$ IFN, IL2, IL3, IL4, IL5, IL7, IL12p40/70 and VCAM1 expression in TM specimens is in line with previous single and multiparametric conventional approaches performed in human TM-derived primary cultures, aqueous and tears [17, 24, 35, 40]. During glaucoma, macrophages produce cytokines including IL6, IL1 $\beta$ and $\mathrm{TNF} \alpha$, leading to an acute inflammatory response. These cytokines can induce ECM remodeling and alter cytoskeletal interactions in the glaucomatous TM [20]. The increased expression of IL6 and IL10 in glaucomatous TMs is in line with the increased IL10 and IL6 levels detected, respectively, in glaucomatous fluids (sera and aqueous) and strongly support the hypothesis of IL10 and IL6 as potential biomarkers of prognosis of disease or therapy $[25,40-43]$. The high expression of IL6 might be explained with the remodeling process occurring in glaucomatous TMs and the IL6-TGF $\beta 1$ cross talk observed in TM-derived primary cultures [40, 43, 44]. IL6 increased outflow facility in perfused anterior segments of porcine eyes and IL6 levels were increased in porcine TM cells as a result of oxidative challenge [45, 46]. Besides, IL6 and IL8 have been implicated in induction of cellular senescence [47]. TNF $\alpha$ and IL6 mediate human microvascular endothelial tight junction modulation, by their ability of cytoskeletal rearrangment [48]. Finally, IL8 was found to modulate the permeability of the Schlemm's canal endothelial cells [49].

On the other hand, the increase of IL7 might be explained with the IL7 ability to counteract the TGF $\beta_{1}$ activity, as observed in other in vitro models [50]. By contrary, the high IL10 expression is actually missing of explanation, although in experimental models of fibrosis the IL10 triggered (i) the anti-inflammatory response through the inhibition of TNF $\alpha$, IL1, IL6, IL8, IL12, MIP1 $\alpha$ and MIP2 $\alpha$ release from monocytes/macrophages (anti-inflammatory response), (ii) the macrophage activity (down-regulating response MMPs/TGF $\beta_{1}$ ) and (iii) the up-regulation of TIMPs $[43,51]$.

Of interest, the significant increase of MIP1 $\alpha$ / $\delta$ and decrease of MIP1 $\beta$ as well as the increase of VCAM1 and decrease of ICAM3 might support the presence of an anti-inflammatory response, as observed in other systems [52]. As for IL10, the increase of MIPs might be involved in the modulation of macrophage migration, the activation of granulocytes and the modulation of IL5, IL3, IL4 and IL12 inflammatory/profibrogenic activity [52]. The high sTNFRI expression might represent a point of interest, since it has been recently reported that this soluble receptor might be involved in the regulation of $\mathrm{TNF} \alpha$ receptor activity [53]. With respect to the significant low expression of IL18 and IL16 actually we have no explanation.

The observation of the overexpression of IgG bands in the electrophoretic profiles might suggest the contribution of B cell implying potential neuroprotective effects, as previously described [31, 54, 55].

Although cumulating data indicate that MMPs and their inhibitors are increased in TMs' tissue and derived cells, our data show no significant variation in MMPs/TIMPs expression, except for MMP2 and TIMP1. This finding might be consistent with a 
steady-fibrotic status and/or the presence of some inhibitory feedbacks due to endogenous/ exogenous factors [56]. Physiological ECM remodeling occurs via a tight cross talk between MMPs and their tissue-related inhibitors (TIMPs) [6]. The increased MMP2, the unchanged MMP9/MMP13 and the decreased MMP7/TIMP1 expression might be the result of an excessive ECM accumulation and a low proteolytic activity $[6,7,10]$. One explanation for this result might be the overexpression of $\mathrm{VEGF} / \mathrm{TGF} \beta_{1}$ (profibrogenic factors), IL7 (inhibitor of fibrosis) and/IL6/IL12/ IL10/IL5/IL4/IL3 (profibrogenic cytokines), all directly/indirectly involved in the tissue remodeling process $[20,21,57,58]$. Another explanation might lie in the eye-drop therapy, since in addition to endogenous factors and ECM-derived products, the exogenous medications might influence TM remodeling, representing a side-effect of the therapy [56]. Both endogenous (increased IOP) and exogenous-induced (medications) biomolecular changes might actively contribute to the biomechanical features of obstructive TM. It is noteworthy to highlight that the therapy usually starts with medications for reducing IOP in order to delay/prevent glaucoma progression [55]. Hence, our POAG population is represented by patients chronically treated with IOP-lowering eye-drops and not undergoing previous surgery. Therefore, the possibility that TM specimens collected at the time of trabeculectomy might express a protein profile potentially influenced by the topical therapy cannot be excluded. It should be also noted that in this study population no corticosteroids/ antibiotics therapy was used before trabeculectomy. It is well known that the therapy can alter gene expression of the TM influencing the results of our research, but this is what really happens in all glaucoma patients who daily use antiglaucoma drugs to counteract the development of the disease [59]. Therefore, although it is not possible (in this study) to eliminate the influences and interference of therapy, the proteins found reflect the real profile of glaucomatous proteome.

Altogether the protein chip-based array indicates some new factors (IL7, MIPs, sTNF $\alpha$ RI) and confirm some old ones (IL10, IL6, IL5, IL12, VEGF, TGF $\beta_{1}$ and NGF), all indicative of an active inflammatory process, as previously described [60, 61]. Indeed, both protein and mRNA evaluations highlight the presence of an active process of tissue remodeling and angiogenesis (MMP2, MMP7, VEGF, TGF $\beta_{1}$ ). Current studies are underway to correlate this glaucomatous TM expression with those of some glaucomatous body fluids (aqueous, tears and blood).

\section{CONCLUSION}

The possibility to define some factors in glaucomatous TMs potentially associated with disease and correlate this expression in glaucomatous body fluids represents a step forward in the management of glaucoma.

\section{ACKNOWLEDGMENTS}

Many thanks to Dr. Roberto Sacco (Laboratory of Molecular Psychiatry and Neurogenetics, UCBM, Rome, Italy) for microarray statistical support and Dr. Roberta Pastorelli (Protein and Gene Biomarkers Unit, Department of Environmental Health Sciences, IRCCS-Istituto di Ricerche Farmacologiche "Mario Negri", Milan, Italy) for protein array critical suggestions. The study was partially supported by the Fondazione Roma, the Italian Ministry of 
Health and the "National 5xMille 2010 tax donation to IRCCS-G.B. Bietti Foundation". The funders had no role in study design, data collection and analysis, decision to publish, or preparation of the manuscript. The authors have declared that no competing interests exist. This work is dedicated to the memory of our colleague and friend Prof. Marco Centofanti (M.C.; IRCCS- G.B. Bietti and Tor Vergata University) who recently passed away.

All named authors meet the International Committee of Medical Journal Editors (ICMJE) criteria for authorship for this manuscript, take responsibility for the integrity of the work as a whole, and have given final approval for the version to be published.

Disclosures. A. Micera, L. Quaranta, G. Esposito, I. Floriani, A. Pocobelli, S. C. Saccà, I. Riva, G. Manni, F. Oddone have nothing to disclose.

Compliance with Ethics Guidelines. All procedures followed were in accordance with the ethical standards of the responsible committee on human experimentation (institutional and national), with the Helsinki Declaration of 1964, as revised in 2013, and was reviewed/approved by the institutional Ethic Committee (IRCCS IFO—Fondazione Bietti). A written informed consent was signed by patients joining the study and undergoing surgical therapy.

Open Access. This article is distributed under the terms of the Creative Commons Attribution-NonCommercial 4.0 International License (http://creativecommons.org/licenses/ by-nc/4.0/), which permits any noncommercial use, distribution, and reproduction in any medium, provided you give appropriate credit to the original author(s) and the source, provide a link to the Creative Commons license, and indicate if changes were made.

\section{REFERENCES}

1. Quigley HA. Number of people with glaucoma worldwide. Br J Ophthalmol. 1996;80:389-93.

2. Kwon $\mathrm{YH}$, Fingert $\mathrm{JH}$, Kuehn $\mathrm{MH}$, Alward WL. Primary open-angle glaucoma. $\mathrm{N}$ Engl J Med. 2009;360:1113-24.

3. Heijl A, Leske MC, Bengtsson B, et al. Reduction of intraocular pressure and glaucoma progression: results from the early manifest glaucoma trial. Arch Ophthalmol. 2002;120:1268-79.

4. Leske MC, Heijl A, Hussein M, et al. Factors for glaucoma progression and the effect of treatment: the early manifest glaucoma trial. Arch Ophthalmol. 2003;121:48-56.

5. Luna C, Li G, Liton PB, et al. Resveratrol prevents the expression of glaucoma markers induced by chronic oxidative stress in trabecular meshwork cells. Food Chem Toxicol. 2009;47:198-204.

6. Haddadin RI, Oh DJ, Kang $\mathrm{MH}$, et al. Thrombospondin-1 (TSP1)-null and TSP2-null mice exhibit lower intraocular pressures. Invest Ophthalmol Vis Sci. 2012;53:6708-17.

7. Sacca SC, Pulliero A, Izzotti A. The dysfunction of the trabecular meshwork during glaucoma course. J Cell Physiol. 2015;230:510-25.

8. Izzotti A, Longobardi M, Cartiglia C, Sacca SC. Proteome alterations in primary open angle glaucoma aqueous humor. J Proteome Res. 2010;9:4831-8.

9. Gonzalez-Iglesias H, Alvarez L, Garcia M, et al. Comparative proteomic study in serum of patients with primary open-angle glaucoma and pseudoexfoliation glaucoma. J Proteom. 2014;98:65-78.

10. Acott TS, Kelley MJ. Extracellular matrix in the trabecular meshwork. Exp Eye Res. 2008;86:543-61.

11. Diskin S, Kumar J, Cao Z, et al. Detection of differentially expressed glycogenes in trabecular meshwork of eyes with primary open-angle glaucoma. Invest Ophthalmol Vis Sci. 2006;47:1491-9.

12. Hann CR, Springett MJ, Wang X, Johnson DH. Ultrastructural localization of collagen IV, 
fibronectin, and laminin in the trabecular meshwork of normal and glaucomatous eyes. Ophthalmic Res. 2001;33:314-24.

13. Alexander JP, Samples JR, Acott TS. Growth factor and cytokine modulation of trabecular meshwork matrix metalloproteinase and TIMP expression. Curr Eye Res. 1998;17:276-85.

14. Wordinger RJ, Lambert W, Agarwal R, Talati M, Clark AF. Human trabecular meshwork cells secrete neurotrophins and express neurotrophin receptors (Trk). Invest Ophthalmol Vis Sci. 2000;41:3833-41.

15. Alexander JP, Samples JR, Van Buskirk EM, Acott TS. Expression of matrix metalloproteinases and inhibitor by human trabecular meshwork. Invest Ophthalmol Vis Sci. 1991;32:172-80.

16. Liu T, Xie L, Ye J, Liu Y, He X. Screening of candidate genes for primary open angle glaucoma. Mol Vis. 2012;18:2119-26.

17. Babizhayev MA. Biomarkers and special features of oxidative stress in the anterior segment of the eye linked to lens cataract and the trabecular meshwork injury in primary open-angle glaucoma: challenges of dual combination therapy with $\mathrm{N}$-acetylcarnosine lubricant eye drops and oral formulation of nonhydrolyzed carnosine. Fundam Clin Pharmacol. 2012;26:86-117.

18. Sacca SC, Centofanti M, Izzotti A. New proteins as vascular biomarkers in primary open angle glaucomatous aqueous humor. Invest Ophthalmol Vis Sci. 2012;53:4242-53.

19. de Kater AW, Shahsafaei A, Epstein DL. Localization of smooth muscle and nonmuscle actin isoforms in the human aqueous outflow pathway. Invest Ophthalmol Vis Sci. 1992;33:424-9.

20. Taurone S, Ripandelli G, Pacella E, et al. Potential regulatory molecules in the human trabecular meshwork of patients with glaucoma: immunohistochemical profile of a number of inflammatory cytokines. Mol Med Rep. 2015;11:1384-90.

21. Kuchtey J, Kunkel J, Burgess LG, et al. Elevated transforming growth factor beta 1 in plasma of primary open-angle glaucoma patients. Invest Ophthalmol Vis Sci. 2014;55:5291-7.

22. Wang H, Wang R, Thrimawithana $\mathrm{T}$, et al. The nerve growth factor signaling and its potential as therapeutic target for glaucoma. Biomed Res Int. 2014;2014:759473.

23. Chua J, Vania M, Cheung CM, et al. Expression profile of inflammatory cytokines in aqueous from glaucomatous eyes. Mol Vis. 2012;18:431-8.
24. Kokotas H, Kroupis C, Chiras D, et al. Biomarkers in primary open angle glaucoma. Clin Chem Lab Med. 2012;50:2107-19.

25. Huang $W$, Chen $S$, Gao $X$, et al. Inflammation-related cytokines of aqueous humor in acute primary angle-closure eyes. Invest Ophthalmol Vis Sci. 2014;55:1088-94.

26. Tezel G, Yang X, Cai J. Proteomic identification of oxidatively modified retinal proteins in a chronic pressure-induced rat model of glaucoma. Invest Ophthalmol Vis Sci. 2005;46:3177-87.

27. Yang Z, Quigley HA, Pease ME, et al. Changes in gene expression in experimental glaucoma and optic nerve transection: the equilibrium between protective and detrimental mechanisms. Invest Ophthalmol Vis Sci. 2007;48:5539-48.

28. Borras T, Brandt CR, Nickells R, Ritch R. Gene therapy for glaucoma: treating a multifaceted, chronic disease. Invest Ophthalmol Vis Sci. 2002;43:2513-8.

29. Cahill DJ. Protein and antibody arrays and their medical applications. J Immunol Methods. 2001;250:81-91.

30. Fan BJ, Wiggs JL. Glaucoma: genes, phenotypes, and new directions for therapy. J Clin Invest. 2010;120:3064-72.

31. Joachim SC, Pfeiffer N, Grus FH. Autoantibodies in patients with glaucoma: a comparison of IgG serum antibodies against retinal, optic nerve, and optic nerve head antigens. Graefes Arch Clin Exp Ophthalmol. 2005;243:817-23.

32. Cui X, Churchill GA. Statistical tests for differential expression in cDNA microarray experiments. Genome Biol. 2003;4:210.

33. Churchill GA. Using ANOVA to analyze microarray data. Biotechniques. 2004;37:173-175, 177.

34. Keller KE, Aga M, Bradley JM, Kelley MJ, Acott TS. Extracellular matrix turnover and outflow resistance. Exp Eye Res. 2009;88:676-82.

35. Opal SM, DePalo VA. Anti-inflammatory cytokines. Chest. 2000;117:1162-72.

36. Stone EM, Fingert JH, Alward WL, et al. Identification of a gene that causes primary open angle glaucoma. Science. 1997;275:668-70.

37. Golubnitschaja O, Flammer J. What are the biomarkers for glaucoma? Surv Ophthalmol. 2007;52(Suppl 2):S155-61.

38. Liton PB, Luna C, Challa P, Epstein DL, Gonzalez P. Genome-wide expression profile of human 
trabecular meshwork cultured cells, nonglaucomatous and primary open angle glaucoma tissue. Mol Vis. 2006;12:774-90.

39. Hewitt AW, Craig JE, Mackey DA. Complex genetics of complex traits: the case of primary open-angle glaucoma. Clin Experiment Ophthalmol. 2006;34:472-84.

40. Liton $\mathrm{PB}$, Luna $\mathrm{C}$, Bodman $\mathrm{M}$, et al. Induction of IL-6 expression by mechanical stress in the trabecular meshwork. Biochem Biophys Res Commun. 2005;337:1229-36.

41. Yang J, Yang P, Tezel G, et al. Induction of HLA-DR expression in human lamina cribrosa astrocytes by cytokines and simulated ischemia. Invest Ophthalmol Vis Sci. 2001;42:365-71.

42. Cvenkel B, Kopitar AN, Ihan A. Inflammatory molecules in aqueous humour and on ocular surface and glaucoma surgery outcome. Mediators Inflamm. 2010;2010:939602.

43. Sorkhabi R, Ghorbanihaghjo A, Javadzadeh A, Motlagh BF, Ahari SS. Aqueous humor hepcidin prohormone levels in patients with primary open angle glaucoma. Mol Vis. 2010;16:1832-6.

44. Liton PB, Li G, Luna C, Gonzalez P, Epstein DL. Cross-talk between TGF-beta1 and IL- 6 in human trabecular meshwork cells. Mol Vis. $2009 ; 15: 326-34$.

45. Liton PB, Challa P, Stinnett S, et al. Cellular senescence in the glaucomatous outflow pathway. Exp Gerontol. 2005;40:745-8.

46. Li G, Luna C, Liton PB, et al. Sustained stress response after oxidative stress in trabecular meshwork cells. Mol Vis. 2007;13:2282-8.

47. Kuilman T, Michaloglou C, Vredeveld LC, et al. Oncogene-induced senescence relayed by an interleukin-dependent inflammatory network. Cell. 2008;133:1019-31.

48. Blum MS, Toninelli E, Anderson JM, et al. Cytoskeletal rearrangement mediates human microvascular endothelial tight junction modulation by cytokines. Am J Physiol. 1997;273:H286-94.

49. Alvarado JA, Alvarado RG, Yeh RF, et al. A new insight into the cellular regulation of aqueous outflow: how trabecular meshwork endothelial cells drive a mechanism that regulates the permeability of Schlemm's canal endothelial cells. Br J Ophthalmol. 2005;89:1500-5.

50. Zhang L, Keane MP, Zhu LX, et al. Interleukin-7 and transforming growth factor-beta play counter-regulatory roles in protein kinase
C-delta-dependent control of fibroblast collagen synthesis in pulmonary fibrosis. J Biol Chem. 2004;279:28315-9.

51. Clarke CJ, Hales A, Hunt A, Foxwell BM. IL-10-mediated suppression of TNF-alpha production is independent of its ability to inhibit NF kappa B activity. Eur J Immunol. 1998;28:1719-26.

52. Bell K, Gramlich OW, Hohenstein-Blaul NVTU, et al. Does autoimmunity play a part in the pathogenesis of glaucoma? Prog Retin Eye Res. 2013;36:199-216.

53. Tezel G. TNF-alpha signaling in glaucomatous neurodegeneration. Prog Brain Res. 2008;173:409-21.

54. Musch DC, Gillespie BW, Lichter PR, et al. Visual field progression in the Collaborative Initial Glaucoma Treatment Study the impact of treatment and other baseline factors. Ophthalmology. 2009;116:200-7.

55. Quaranta L, Biagioli E, Riva I, Rulli E, Poli D, Katsanos A, Floriani I. Prostaglandin analogs and timolol-fixed versus unfixed combinations or monotherapy for open-angle glaucoma: a systematic review and meta-analysis. J Ocul Pharmacol Ther. 2013;29:382-389.

56. Mosaed S, Dustin L, Minckler DS. Comparative outcomes between newer and older surgeries for glaucoma. Trans Am Ophthalmol Soc. 2009;107:127-33.

57. Fuchshofer R, Tamm ER. The role of TGF-beta in the pathogenesis of primary open-angle glaucoma. Cell Tissue Res. 2012;347:279-90.

58. Bollinger KE, Crabb JS, Yuan X, et al. Quantitative proteomics: TGFbeta(2) signaling in trabecular meshwork cells. Invest Ophthalmol Vis Sci. 2011;52:8287-94.

59. Izzotti A, La Maestra S, Micale RT, Longobardi MG, Sacca SC. Genomic and post-genomic effects of anti-glaucoma drugs preservatives in trabecular meshwork. Mutat Res. 2015;772:1-9.

60. Malvitte L, Montange T, Vejux A, et al. Measurement of inflammatory cytokines by multicytokine assay in tears of patients with glaucoma topically treated with chronic drugs. $\mathrm{Br}$ J Ophthalmol. 2007;91:29-32.

61. Pieragostino D, Agnifili L, Fasanella V, et al. Shotgun proteomics reveals specific modulated protein patterns in tears of patients with primary open angle glaucoma naive to therapy. Mol BioSyst. 2013;9:1108-16. 